\author{
International Journal of Chemical and Process Engineering \\ Research \\ 2021 Vol. 8, No. 1, pp. 11-18. \\ $\operatorname{ISSN}(e):$ 2313-0776 \\ $\operatorname{ISSN}(p): 2313-2558$ \\ DOI: 10.18488/journal.65.2021.81.11.18 \\ (C) 2021 Conscientia Beam. All Rights Reserved.

\title{
METHYLENE BLUE AND IRON (II) ADSORPTION ONTO RAPHIA HOOKERI SEED: A COMPARATIVE EQUILIBRIUM ISOTHERM STUDY
}

\author{
P. F. Tarbuka ${ }^{1+}$
}

R. H. Gumus ${ }^{2}$

\author{
${ }^{\prime}$ Department of Chemical Engineering, Federal University of Petroleum \\ Resources, Effurun, Delta State, Nigeria. \\ Email:tarbuka.pereware@fupre.edu.ng Tel:+234.8039178743 \\ 'Department of Chemical and Petroleum Engineering, Niger Delta \\ University, Wilberforce Island, Amassoma, Bayelsa State, Nigeria. \\ Email:rhodagumus@ndu.edu.ng
}

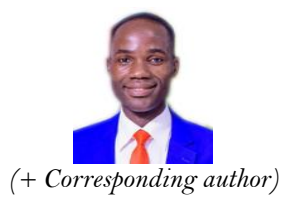

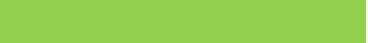

Article History

Received: 23 July 2021 Revised: 25 August 2021 Accepted: 10 September 2021 Published: 27 September 2021

\section{Keywords \\ Iron (II) \\ Sorbate \\ Isotherm \\ Biosorbent \\ Adsorption \\ Parameters \\ Equilibrium \\ Methylene blue \\ Raphia hookeri \\ Activated carbon.}

\section{ABSTRACT}

In this study, activated carbon prepared from Raphia hookeri seed was employed as an adsorbent to take up methylene blue (an organic ion-in-solution) and iron (II), a metal ion-in-solution. The biosorbent was prepared using chemical activation using sodium hydroxide $(\mathrm{NaOH})$ as an impregnating agent. Calibration was performed with a focus on the change in the adsorbate concentration. The equilibrium isotherms study was conducted by considering a range of sorbate concentrations, to determine the optimal conditions for the adsorption systems. The same sorbate volume $(10 \mathrm{ml})$, and the same dosage $(0.3 \mathrm{~g})$ of biosorbent were used for both adsorption processes. Linear analysis was used to compare the best-fitting isotherms. Langmuir, Freundlich, and Dubinin-Radushkevich models were tested. The highest coefficient of determination values $\left(\mathrm{R}^{2}\right)$ for both iron (II) and Methylene blue was obtained from the Langmuir isotherm as 0.9266 and 0.9572 , respectively, compared to values from the other isotherms tested - indicative of Langmuir isotherm's superior fit. Estimated values of 'separation factor', $K_{R}$, for Methylene blue (0.29457), however, was lower than that of iron (II) (0.42141) - an indication that the sorbent treats methylene blue better than iron (II), though both processes are feasible.

Contribution/Originality: This study is one of very few studies which have investigated the comparative feasibility of treating water polluted by Iron (II) and Methylene blue, using biosorbent from Raphia hookeri seed.

\section{INTRODUCTION}

To optimise the design of a sorption system, where the adsorbent of consideration is feasible (or in any case), finding out the most appropriate correlation for the equilibrium adsorption study is such an important prerequisite [1,2]. Equilibrium isotherm equations are developed and used to describe the experimental adsorption data [3]. Resultant values of various isotherm parameters obtained from their corresponding correlations provide vital information on the adsorption mechanisms, surface properties and the feasibility of the adsorption system. These isotherm equations can be used for certain purposes, such as the design of columns/systems that would perform effectively adsorption [4, 5].

An investigation of the feasibility or adsorptivity of activated carbon prepared from Raphia palm seed, to remove metal ions and organic pollutants from aqueous solutions, and to test the dual adsorption processes with isotherm models, is what is been studied. The experiments, to obtain relevant data, were performed over a period of 
60 min. For solid-liquid systems, several isotherms are available but Langmuir, Freundlich and DubininRadushkevich (D-R) isotherms were used to analyse the adsorption equilibrium. The various forms of the isotherms are presented in Table 1.

\section{MATERIALS AND METHOD}

\subsection{Preparation of the Biosorbent}

Raphia palm (Raphia hookeri) seeds (which are disposed of as waste) were collected from a commercial (Raphia mesocarp) trader at Famgbe community in Yenagoa Local Government Area of Bayelsa State. They were washed and sun-dried for three days and oven-dried at $105^{\circ} \mathrm{C}$ for 24 hours. The oven-dried precursors, after cooling, were weighed to determine the mass before carbonization and activation. Carbonisation, each in $90 \mathrm{~min}$, was done at three temperatures $400^{\circ} \mathrm{C}, 500^{\circ} \mathrm{C}$ and $600^{\circ} \mathrm{C}$ that are the optimal thermal treatment conditions for Raphia palm seed (RPS) during carbonisation, according to Akpos [6]. The carbonized precursor was treated with a 0.3 Molar solution of sodium hydroxide for $24 \mathrm{~h}$; after which activation was done, for each batch, at $700^{\circ} \mathrm{C}$.

\subsection{Preparation of Sorbate \\ 2.2.1. Preparation of Iron (II) Solutions}

Six, 100ml volumetric, flasks were labelled with masking tapes. Five of them had inscriptions of $0.1 \mathrm{ppm}$, $0.2 \mathrm{ppm}, 0.5 \mathrm{ppm}$, 1.0ppm and 2.5ppm respectively. The sixth flask was labelled 'blank'. An equivalent volume of 1.0, 2.0, 5.0, 10.0, and $25 \mathrm{ml}$ of the iron stock, prepared from $\mathrm{Fe}\left(\mathrm{NH}_{4}\right)_{2}\left(\mathrm{SO}_{4}\right) \cdot 6 \mathrm{H}_{2} \mathrm{O}$, was pipetted into the flasks in that order; except in the blank (in which only $50 \mathrm{ml}$ of distilled water was added at this stage). Then, the following reagents were serially added to all the six volumetric flasks: $1.0 \mathrm{ml}$ of hydroxylamine hydrochloride, $5.0 \mathrm{ml}$ of 1-10 Phenanthroline and $8.0 \mathrm{ml}$ of sodium acetate. The development of an orange-red colour indicates iron [7] and the intensity of the colour is in concordance with the concentration (i.e. showing serial dilution).

\subsubsection{Preparation of Methylene Blue Solutions}

A stock solution of methylene blue was prepared using 1 gram of the reagent dissolved in a 1000ml volumetric flask. Serial dilutions were made into $100 \mathrm{ml}$ volumetric flasks. Five solutions, 0.5, 1.0, 1.5, 2.0, and 2.5ppm, respectively, were obtained for calibrating the spectrophotometer). These dilutions were also used for the adsorption process.

\subsection{The Adsorption Process}

To perform equilibration, $0.3 \mathrm{~g}$ of $300 \mu \mathrm{m}$ biosorbent, carbonized at $600^{\circ} \mathrm{C}$, was put in five test tubes for iron (II) and methylene blue experiments. For the iron (II) experiment, the concentration was varied in this order: 0.1 , 0.2, 0.5, 1, $2.5 \mathrm{ppm}$, while the Methylene blue (MB) concentrations were 0.5, 1.0, 1.5, 2.0, 2.5 ppm, respectively. Each test tube contained a 10-ml solution. The tubes were stoppered, labelled and equilibrated in HY-4A Cycling Vibrator/Shaker for 1 hour at $31.5^{\circ} \mathrm{C}$. Then, the tubes were centrifuged at 3500 rpm for five minutes. Decantation and further filtration were done to obtain particles-free samples, for experimentation in a spectrophotometer.

\section{RESULTS AND DISCUSSION}

Equation 1 plays a fundamental role in the development of models for any adsorption system. Data and parameters generated, for both iron (II) and methylene blue adsorption systems, in this study, were fitted into Langmuir, Freundlich and D-R adsorption isotherms. Among other process parameters, varied concentration changes controlled the isotherm studies. 


\subsection{Effect of Initial Concentration}

In the study of the effect of concentration, it was observed that the percentage of iron (II) adsorbed decreases with increasing initial concentration and maximum adsorption was obtained at the least concentration. However, because of the concentration driving force, from the sorbate, which favours adsorption more than possible desorption, higher concentrations recorded pretty high uptake unto the sorbent compared to the mid-range concentrations. While the plot on iron (II) sorption capacity takes the form of a parabola with two highs, the Methylene Blue counterpart is a straight line: showing a continuous increase in percentage uptake from the lowest to the highest concentration [8]. This is obviously because a higher Methylene Blue concentration means a greater driving force for mass transfer from the aqueous solution to the solid adsorbent. Figure 1 presents the data showing the effect of the initial concentration on adsorption.

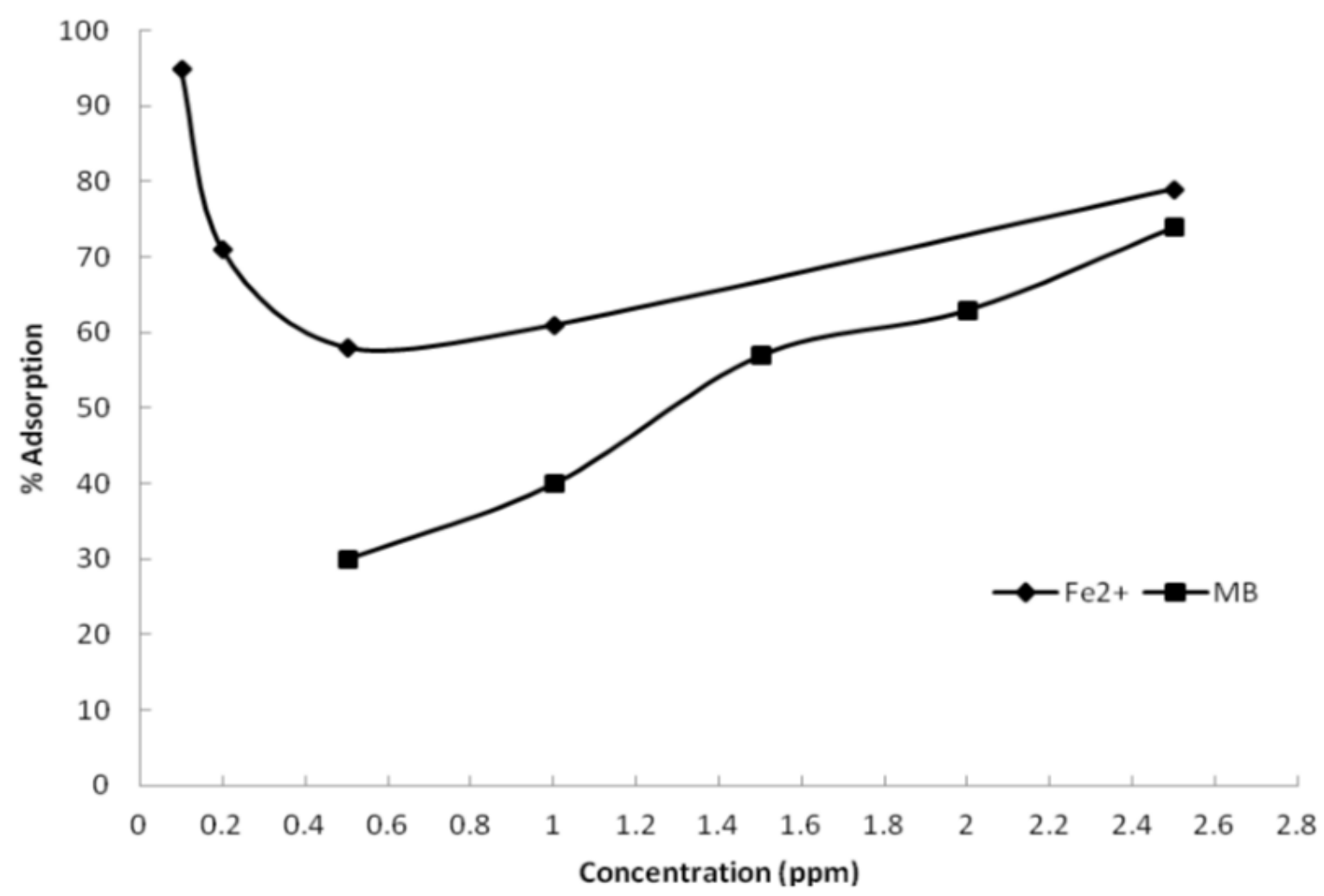

Figure-1. Effect of initial concentration of $\mathrm{Fe}^{2+}$ and MB. Dosage $=0.3 \mathrm{~g}$; particle size $=300 \mu \mathrm{m}$, carbonised at $600^{\circ}$; contact time $=1$ hour.

\subsection{Adsorption Isotherm Studies}

o generate data for equilibrium studies Equation 1 presents the choice of the parameter to vary and which to keep constant in determining equilibrium concentrations that would be used in developing models representing each isotherm. This implies that anyone between adsorbate concentration, adsorbent dosage or sorbate volume can be varied at a time while the remaining two of the trio (and other parameters considered in the experiment) are kept constant. Ho, in his studies, made similar assertions in trying to explain how to obtain data for isotherm studies [9].

$$
\mathrm{qe}=\frac{(\mathrm{Ci}-\mathrm{Ce}) \mathrm{V}}{\mathrm{w}}(\mathrm{mg} / \mathrm{g})
$$

Where $\mathrm{q}_{\mathrm{e}}=$ adsorption capacity; $\mathrm{C}_{\mathrm{i}}=$ Initial concentration of adsorbate; $\mathrm{C}_{\mathrm{o}}=$ Final or equilibrium concentration of the adsorbate; $\mathrm{V}$ = volume of adsorbate used; $\mathrm{w}=$ quantity of adsorbent used. 
Table-1. Non-linear and linear forms of adsorption isotherms.

\begin{tabular}{|c|c|c|c|c|}
\hline Isotherm & & Linear Form & Plot & Reference(s) \\
\hline Freundlich & $q_{e}=K_{F} C_{e}^{1 / n}$ & $\log \left(q_{\theta}\right)=\log \left(K_{F}\right)+1 / n \log \left(C_{\theta}\right)$ & $\log \left(q_{\theta}\right)$ vs $\log \left(C_{B}\right)$ & \multirow{5}{*}[2,10]{} \\
\hline Langmuir- 1 & \multirow{4}{*}{$q_{e}=\frac{q_{m} K_{a} C_{e}}{1+K_{a} C_{e}}$} & $\frac{C_{e}}{q_{e}}=\frac{1}{q_{m}} C_{e}+\frac{1}{K_{a} q_{m}}$ & $\frac{C_{e}}{q_{e}} v s C_{e}$ & \\
\hline Langmuir -2 & & $\frac{1}{q_{e}}=\left(\frac{1}{K_{a} q_{m}}\right) \frac{1}{C_{e}}+\frac{1}{q_{m}}$ & $\frac{1}{q_{e}} v s \frac{1}{C_{e}}$ & \\
\hline Langmuir -3 & & $q_{e}=q_{m}-\left(\frac{1}{K_{a}}\right) \frac{q_{e}}{C_{e}}$ & $q_{e} \operatorname{vs} \frac{q_{e}}{C_{e}}$ & \\
\hline Langmuir - 4 & & $\frac{q_{e}}{C_{e}}=K_{a} q_{m}-K_{a} q_{a}$ & $\frac{q_{e}}{C_{e}} v s q_{e}$ & \\
\hline $\mathrm{D}-\mathrm{R}$ & & $\operatorname{In} q_{e}=\operatorname{In} q_{m}-\beta \varepsilon^{2}$ & $\ln q_{e} v s \varepsilon^{2}$ & {$[11]$} \\
\hline
\end{tabular}

\subsection{Langmuir Isotherm Analysis}

The simple assumption of the Langmuir isotherm is that adsorption occurs at specific homogeneous sites within the adsorbent [12]; expressing a monolayer behaviour, which implies that once an adsorbate molecule enters a certain pore space inside the adsorbent no other molecule goes into the same space. The Langmuir equation and its linear forms are expressed in Table 1. Where: $\mathrm{q}_{\mathrm{e}}=$ amount of metal iron adsorbed $\left(\mathrm{mg} \cdot \mathrm{g}^{-1}\right)$ at equilibrium; $\mathrm{q}_{\mathrm{m}}=$ maximum amount of metal iron adsorbed $\left(\mathrm{mg} \cdot \mathrm{g}^{-1}\right) ; \mathrm{C}_{\mathrm{e}}=$ Final concentration of metal iron in solution $\left(\mathrm{mg} \cdot \mathrm{L}^{-1}\right) ; \mathrm{K}_{\mathrm{a}}=$ Langmuir or equilibrium constant for adsorption $\left({\left.\mathrm{L} . \mathrm{mg}^{-1}\right)}^{-1} \mathrm{~K}_{\mathrm{a}}\right.$, and $\mathrm{q}_{\mathrm{e}}$ are obtained from the intercept and slope when any linear form of the isotherm is plotted. The essential isotherm parameters of the Langmuir adsorption isotherm can be used to obtain a dimensionless quantity (called separation factor), which is used to predict the affinity between the sorbate and sorbent [13, 14]. As presented in Equation 2, the separation factor also called equilibrium parameter, $\mathrm{K}_{\mathrm{R}}$, is expressed as one divided by the encapsulation of one plus the product of the Langmuir (or equilibrium) constant, $\mathrm{K}_{\mathrm{a}}$ and the initial concentration, $\mathrm{C}_{0}$, shown below:

$$
\mathrm{K}_{\mathrm{R}}=\frac{1}{1+\mathrm{K}_{\mathrm{a}} \mathrm{C}_{\mathrm{0}}}
$$

In this study, a test on the four forms of Langmuir was done using the experimental data. It was observed that both adsorption systems fitted better into the linear form of Langmuir 2 compared to the other three forms. Hence, it was used as the choice linear form for the Langmuir isotherm studies with the plots shown in Figure 2. An estimation of the $\mathrm{K}_{\mathrm{R}}$ values (in Table 2) justifies the conclusion that iron II $\left(\mathrm{F}^{2+}\right)$ and $\mathrm{MB}$ adsorption on modified raphia palm seed activated carbon (RPSAC) is favourable; since $0<K_{R}<1$ is true for both sorbate [15]. However, the smaller value for $\mathrm{MB}$ compared to that of $\mathrm{Fe}^{2+}$ indicates that the sorption of $\mathrm{MB}$ is more favourable [16]. Nonetheless, the adsorbent is observed as appropriate in treating both classes of pollutants in water: this conclusion is because, though the average coefficient of determination for the $\mathrm{F}^{2+}$ experiments is lower than that of $\mathrm{MB}$, its nearness to unity is a sufficient indication that enough iron-deposit is removed from the water body and has reduced iron-in-water to a permissible range.

\subsection{Freundlich Adsorption Isotherm}

The Freundlich adsorption isotherm is originally an empirical model but was later interpreted as biosorption onto heterogeneous surfaces (that is, surfaces supporting sites of varied affinities). And it is now widely used for data obtained from experiments [17]. The Freundlich isotherm is applied to estimate the adsorption intensity of the adsorbent towards the adsorbate [18]. From the Freundlich equation in Table 1 above $K_{F}$ and $1 / n$ are 
Freundlich constants representing adsorption capacity and adsorption intensity, respectively [19]. The Freundlich isotherm is commonly considered an empirical proposition, relating $q$ and c using the power of the inverse of $n$ and $K_{\mathrm{F}}$ as the equilibrium constant. Despite being empirical, the Freundlich model often provides a brilliant explanation for isotherms experimentally obtained from liquid-phase adsorption studies [20].

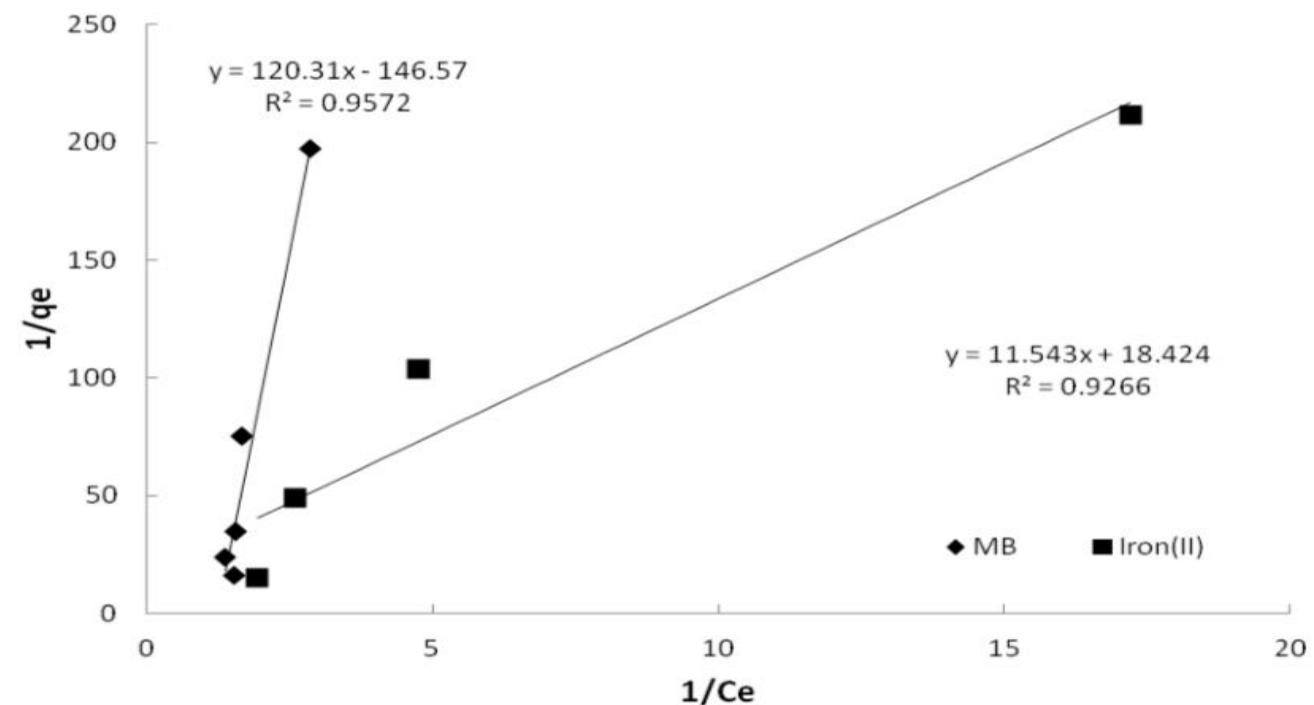

Figure-2. Langmuir adsorption isotherms for the adsorption of $\mathrm{Fe}^{2+}$ and Methylene Blue onto RPSAC at $31.5^{\circ} \mathrm{C}$; adsorbent size $=300 \mu \mathrm{m}$; carbonisation temperature $=600^{\circ} \mathrm{C}$ ).

A straight line from a plot of the Freundlich isotherm, as shown in Figure 3, explains the degree of linearity and further tells the type of adsorption. If $n=1$, then adsorption is linear; if $n<1$, then adsorption is a chemical process; if $\mathrm{n}>1$, then adsorption is a physical process [21, 22]. In this study, the $n$ values for iron (II) and methylene blue are 0.942 and 0.330 respectively. This result indicates that the adsorption of each adsorbate onto RPSAC is a chemisorption process.



Figure-3. Freundlich adsorption isotherms for the adsorption of $\mathrm{Fe}^{2+}$ and Methylene Blue onto RPSAC. 


\subsection{Dubinin-Radushkevich Isotherm}

This isotherm model is commonly used to estimate the characteristic porosity of the biomass/adsorbent and the apparent or mean free energy of the adsorption process [23, 24]. The terms expressed in Table 1 for the D-R isotherm are defined as follows:

$\mathrm{q}_{\mathrm{m}}=$ theoretical saturation capacity. The higher the values of $\mathrm{q}_{\mathrm{m}}$, the higher the adsorption capacity.

$\mathrm{q}_{\mathrm{e}}=$ equilibrium solid phase concentration.

$\varepsilon=$ Polanyi potential is expressed mathematically, in Equation 3:

$$
\varepsilon=\operatorname{RTIn}\left(1+1 / \mathrm{C}_{\mathrm{e}}\right)
$$

Where:

$\mathrm{T}=$ Absolute temperature $(\mathrm{K})$.

$\mathrm{R}=$ Universal gas constant.

$\beta=$ a constant related to the adsorption energy as presented in Equation 4:

$$
\mathbf{E}=(2 \beta)^{-1 / 2}
$$

Where $\mathbf{E}=$ Sorption mean free energy.

Linear plots of the D-R isotherm for sorption of both iron (II) and methylene blue

Onto raphia hookeri seed is presented in Figure 4 below.

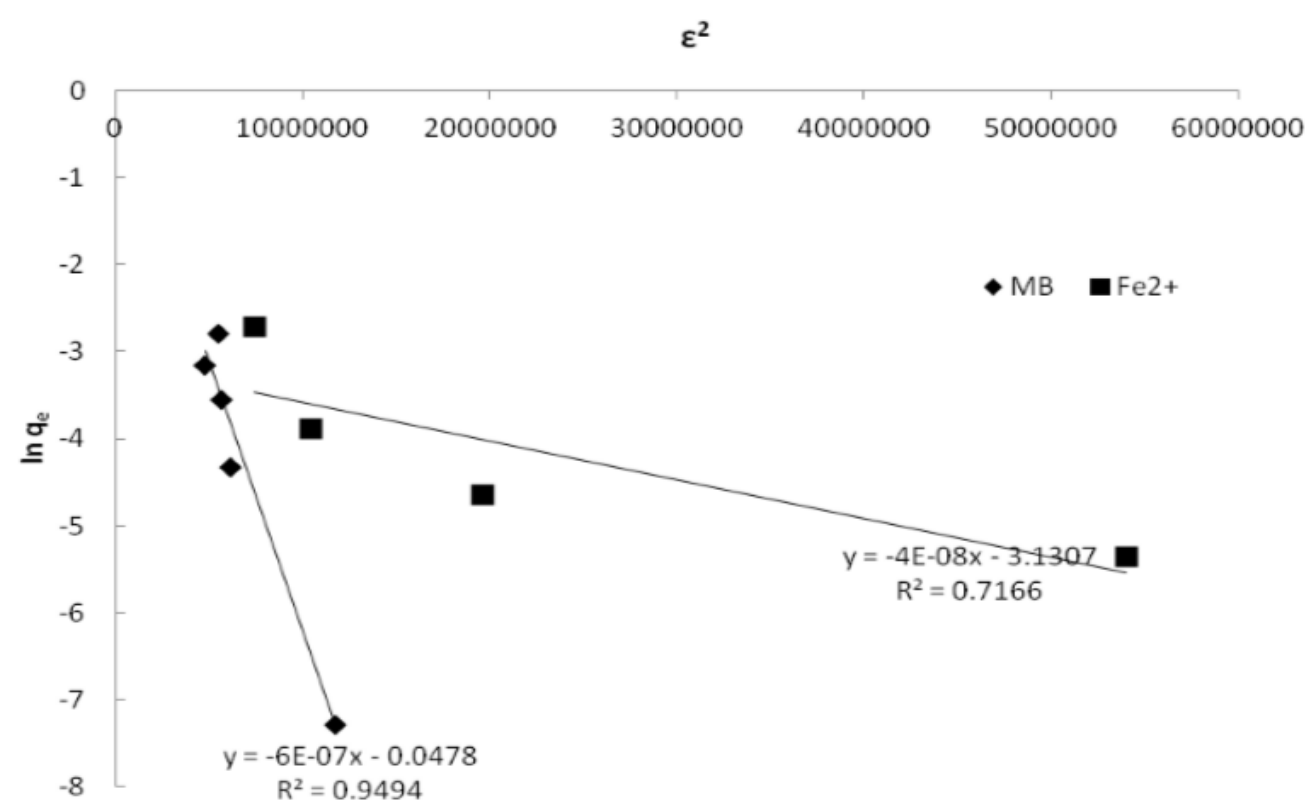

Figure-4. Dubinin-Radushkevich adsorption isotherms for the adsorption of $\mathrm{Fe}^{2+}$ and Methylene blue onto RPSAC at $31.5^{\circ} \mathrm{C}$; adsorbent size $=300 \mu \mathrm{m}$; carbonisation temperature $=600^{\circ} \mathrm{C}$.

\begin{tabular}{|c|c|c|c|c|}
\hline Isotherm & Parameters & Unit & $\mathbf{F}^{2+}$ & MB \\
\hline \multirow[t]{4}{*}{ Langmuir } & $\mathrm{q}_{\mathrm{m}}$ & $\mathrm{mg} / \mathrm{g}$ & 0.0543 & 0.00687 \\
\hline & $\mathrm{K}_{\mathrm{a}}$ & $\mathrm{gm}^{3} / \mathrm{mg}$ & 1.59652 & 1.215079 \\
\hline & $\mathrm{K}_{\mathrm{R}}$ & & 0.42141 & 0.29457 \\
\hline & $\mathrm{R}^{2}$ & & 0.9266 & 0.9583 \\
\hline \multirow[t]{3}{*}{ Freundlich } & $1 / n$ & & 1.0611 & 3.0333 \\
\hline & $\mathrm{K}_{\mathrm{F}}$ & $(\mathrm{mg} / \mathrm{g})\left(\mathrm{dm}^{3} / \mathrm{mg}\right)^{1 / \mathrm{n}}$ & 0.07759 & 0.114921 \\
\hline & $\mathrm{R}^{2}$ & & 0.8343 & 0.7979 \\
\hline \multirow[t]{3}{*}{ D-R } & $\beta$ & $\mathrm{Mol}^{2} / \mathrm{J}^{2 \mathrm{~S}}$ & $-4.0 \mathrm{E}-08$ & $-6.00 \mathrm{E}-07$ \\
\hline & $\mathrm{q}_{\mathrm{m}}$ & $\mathrm{mg} / \mathrm{g}$ & 0.04369 & 0.953324 \\
\hline & $\mathrm{R}^{2}$ & & 0.7166 & 0.9494 \\
\hline
\end{tabular}

Table-2. Isotherm parameters obtained using the linear method. 


\section{CONCLUSION}

The result indicates the suitability of raphia palm seed activated carbon for the removal of both pollutant types. Langmuir, Freundlich and Dubinin-Radushkevich isotherm models were used to represent the experimental data. Based on the high values of the coefficient of correlation $\left(\mathrm{R}^{2}=0.9266\right.$ and 0.9572 for iron and MB respectively) obtained from the linear plots, Langmuir isotherm was found to give the best fit for both adsorption systems. More so, separation factors, for both sorbate, obtained from the Langmuir isotherm parameters showed favourability of the twain adsorption processes; with $K_{R}$ values less than 1 . However, the $K_{R}$ value for MB (0.29457) was lower than that of $\mathrm{Fe}^{2+}(0.42141)$, which is a suggestion that the biosorbent treats methylene blue better than iron (II).

Funding: This study received no specific financial support.

Competing Interests: The authors declare that they have no competing interests.

Acknowledgement: Both authors contributed equally to the conception and design of the study.

\section{REFERENCES}

[1] K. Riahi, S. Chaabane, and B. B. Thayer, "A kinetic modeling study of phosphate adsorption onto phoenix dactylifera L. date palm fibers in batch mode," Journal of Saudi Chemical Society, vol. 21, pp. S143-S152, 2017. Available at: https://doi.org/10.1016/j.jscs.2013.11.007.

[2] B. Armagan and F. Toprak, "Optimum isotherm parameters for reactive azo dye onto pistachio nut shells: Comparison of linear and non-linear methods," Polish Journal of Environmental Studies, vol. 22, pp. 1007-101 1, 2013.

[3] T. Smitha, S. Thirumalisamy, and S. Manonmani, "Equilibrium and kinetics study of adsorption of crystal violet onto the peel of Cucumis sativa fruit from aqueous solution," E-Journal of Chemistry, vol. 9, pp. 1091-1101, 2012. Available at: https://doi.org/10.1155/2012/457632.

[4] S. J. Kulkarni and A. K. Goswami, "Characterization, treatment and disposal of sludge: A review," International Journal for Research in Applied Science and Engineering Technology, vol. 2, pp. 516-517, 2014.

[5] I. Mobasherpour, E. Salahi, and A. Asjodi, "Research on the batch and fixed-bed column performance of red mud adsorbents for lead removal," Canadian Chemical Transactions, vol. 2, pp. 83-96, 2013. Available at: https://doi.org/10.13179/canchemtrans.2014.02.01.0059.

[6] E. Akpos, Production and characterization of activated carbon from Raphia Africana Otedoh Seed for adsorption of basic red 29 Dye’. Bayelsa State, Nigeria: Niger Delta University Wilberforce Island, 2016.

[7] C. S. Gundewar, Government of India ministry of mines chemical and instrumental analysis of project credit. Indian Bur: Mines, 2012.

[8] L. Wang and J. Li, "Removal of methylene blue from aqueous solution by adsorption onto Crofton weed stalk," BioResources, vol. 8, pp. 2521-2536, 2013. Available at: https://doi.org/10.15376/biores.8.2.2521-2536.

[9] Y.-S. Ho, R. Malarvizhi, and N. Sulochana, "Equilibrium isotherm studies of methylene blue adsorption onto activated carbon prepared from delonix regia pods," Journal of Environmental Protection Science, vol. 3, pp. 111-116, 2009.

[10] Y. S. Ho, "Isotherms for the sorption of lead onto peat: Comparison of linear and non-linear methods," Polish Journal of Environmental Studies, vol. 15, pp. 81-86, 2005.

[11] U. Edet and A. Ifelebuegu, "Kinetics, isotherms, and thermodynamic modeling of the adsorption of phosphates from model wastewater using recycled brick waste," Processes, vol. 8, p. 665, 2020. Available at: https://doi.org/10.3390/pr8060665.

[12] L. A. A. Pinto, J. S. Piccin, and G. L. Dotto, "Adsorption isotherms and thermochemical data of FD\&C Red $n^{\circ} 40$ binding by Chitosan_php," Brazilian Journal of Chemical Engineering, pp. 1-11, 2017. Available at: http://dx.doi.org/10.1590/S0104?66322011000200014.

[13] A. P. Olalekan, A. O. Dada, and A. O. Okewale, "Comparative adsorption isotherm study of the removal of Pb2+ and Zn2+ Onto agricultural waste," Research Journal of Chemical and Environmental Sciences, vol. 5, pp. 69-74, 2014. 
[14] M. B. Desta, "Batch sorption experiments: Langmuir and Freundlich Isotherm studies for the adsorption of textile metal ions onto teff straw (Eragrostis tef) agricultural waste," Journal of Thermodynamics, vol. 2013, pp. 1-6, 2013.

[15] M. Erhayem, F. Al-Tohami, R. Mohamed, and K. Ahmida, "Isotherm, kinetic and thermodynamic studies for the sorption of mercury (II) onto activated carbon from Rosmarinus Officinalis leaves," American Journal of Analytical Chemistry, vol. 6, pp. 1-10, 2015. Available at: https://doi.org/10.4236/ajac.2015.61001.

[16] A. Dada, A. Olalekan, A. Olatunya, and O. Dada, "Langmuir, Freundlich, Temkin and Dubinin-Radushkevich isotherms studies of equilibrium sorption of Zn2+ unto phosphoric acid modified rice husk," IOSR Journal of Applied Chemistry, vol. 3, pp. 38-45, 2012. Available at: https://doi.org/10.9790/5736-0313845.

[17] R. Gumus, "Kinetic studies of methylene blue adsorption on to activated carbon prepared from plantain pod (Musa paradisiac)," British Journal of Applied Science $\&$ Technology, vol. 15, pp. 1-14, 2016. Available at: https://doi.org/10.9734/bjast/2016/24079.

[18] J. C. Igwe and A. Abia, "Adsorption isotherm studies of Cd (II), Pb (II) and $\mathrm{Zn}$ (II) ions bioremediation from aqueous solution using unmodified and EDTA-modified maize cob," Eclética Química, vol. 32, pp. 33-42, 2007.

[19] N. Ayawei, Ebelegi, A. N. and D. Wankasi, "Modelling and interpretation of adsorption isotherms," Journal of Chemistry, vol. 2017, pp. 1-11, 2017. Available at: https://doi.org/10.1155/2017/3039817.

[20] C. Na, "Size-controlled capacity and isocapacity concentration in Freundlich adsorption," ACS Omega, vol. 5, pp. 13130-13135, 2020. Available at: https://doi.org/10.1021/acsomega.0c01144.

[21] M. B. Desta, "Batch sorption experiments: Langmuir and Freundlich isotherm studies for the adsorption of textile metal ions onto teff straw (eragrostis tef) agricultural waste," Journal of Thermodynamics, vol. 1, pp. 1-6, 2013. Available at: https://doi.org/10.1155/2013/375830.

[22] A. Elkhaleefa, I. H. Ali, E. I. Brima, I. Shigidi, A. Elhag, and B. Karama, "Evaluation of the adsorption efficiency on the removal of lead (II) Ions from aqueous solutions using Azadirachta indica leaves as an adsorbent," Processes, vol. 9, p. 559, 2021 . Available at: https://doi.org/10.3390/pr9030559.

[23] P. Sampranpiboon, P. Charnkeitkong, and X. Feng, "Equilibrium isotherm models for adsorption of zinc (II) ion from aqueous solution on pulp waste," WSEAS Transactions on Environment and Development, vol. 10, pp. 35-47, 2014. Available at: https://doi.org/10.1023/b:adso.0000024038.32712.18.

[24] I. H. Ali, M. K. Al Mesfer, M. I. Khan, M. Danish, and M. M. Alghamdi, "Exploring adsorption process of lead (II) and chromium (VI) ions from aqueous solutions on acid-activated carbon prepared from Juniperus procera leaves," Processes, vol. 7, p. $217,2019$.

Views and opinions expressed in this article are the views and opinions of the author(s), International Journal of Chemical and Process Engineering Research shall not be responsible or answerable for any loss, damage or liability etc. caused in relation to/arising out of the use of the content. 